\title{
Confirmation of Glyphosate- and Acetolactate Synthase (ALS)-Inhibitor-Resistant Kochia (Kochia scoparia) in Nebraska
}

\author{
Neha Rana ${ }^{1} \&$ Amit J. Jhala ${ }^{1}$ \\ ${ }^{1}$ Department of Agronomy and Horticulture, University of Nebraska-Lincoln, Lincoln, NE, USA \\ Correspondence: Amit J. Jhala, Department of Agronomy and Horticulture, University of Nebraska-Lincoln, \\ Lincoln, NE 68583, USA. Tel: 1-402-472-1534. E-mail: amit.jhala@unl.edu
}

Received: July 22, 2016

doi:10.5539/jas.v8n10p54
Accepted: August 23, $2016 \quad$ Online Published: September 15, 2016

URL: http://dx.doi.org/10.5539/jas.v8n10p54

\begin{abstract}
Kochia is an early emerging weed of increasing concern across the Great Plains region of the United States due to the evolution of resistance to herbicides. Greenhouse studies were conducted to confirm and characterize the level of glyphosate and acetolactate synthase (ALS)-inhibiting herbicide resistance in kochia biotype collected from a field in Sheridan County in Nebraska. The response of kochia biotype to 9 rates (0 to 16×) of tribenuron and glyphosate was evaluated in a whole plant dose-response bioassay. On the basis of the values at the $90 \%$ effective dose $\left(\mathrm{ED}_{90}\right)$, the putative-resistant kochia biotype had a 6- and 15-fold level of resistance to glyphosate and tribenuron, respectively. Future research will evaluate strategies for the management of glyphosate- and ALS-resistant kochia under field conditions.
\end{abstract}

Keywords: glyphosate, acetolactate synthase (ALS)-inhibiting herbicides, resistance management

\section{Introduction}

Kochia [Kochia scoparia (L.) schrad], an annual broadleaf weed species from the Chenopodiaceae family, is native to Eurasia and was introduced to the western hemisphere in the early 1900s as an ornamental plant (Dodd \& Moore, 1993; Friesen et al., 2009). Commonly referred to as Fireweed (Casey, 2009), it is an economically important weed in cropland and non-crop areas including pastures, roadsides, wasteland, and ditchbanks (Forcella, 1985; Beckie et al., 2013). Kochia is a C4 species characterized by early season emergence at low soil temperatures, rapid growth, and high tolerance to heat, drought, and salinity. It is well adapted to the semiarid and arid regions of the Canadian Prairies and the Great Plains of North America (Nussbaum et al., 1985; Schwinghamer \& Van Acker, 2008; Friesen et al., 2009).

In the Midwestern and western United States, kochia has become an increasingly problematic weed with detrimental effects on yields in annual crops, including wheat (Triticum aestivum L.), sorghum [Sorghum bicolor (L.)], sunflower (Helianthus annuus L.), sugar beet (Beta vulgaris L.), corn (Zea mays L.), and soybean [Glycine $\max$ (L.) Merr.]. It is estimated that the interference and competition from kochia reduced crop yields by $30 \%$ to as much as $95 \%$ depending on the density of the kochia and the crop being investigated (Durgan et al., 1990; Forcella, 1985; Weatherspoon \& Schweizer, 1969; Wicks et al., 1993, 1994). Furthermore, kochia is a weed of major concern because it has evolved resistance to number of herbicide chemistries (Friesen et al., 2009). Kochia seed viability is short-lived in the soil, with low seed dormancy impacting the turnover time for favorable fitness traits to become predominant in the population (Anderson \& Nielsen, 1996; Schwinghamer \& Van Acker, 2008). In addition, kochia is wind-pollinated and seed dispersal from resistant plants tumble across fields, allowing for the rapid spread of resistance. Thus, herbicide-resistant kochia has become prevalent in areas where herbicide(s) with the same mode of action have been used repeatedly (Crespo et al., 2014).

Kochia is a weed species that has evolved resistance as early as 1970s; the first case of triazine-resistant kochia was reported in 1976 in a Kansas corn field (Heap, 2016). A decade later, 5 years after commercialization of the first sulfonylurea herbicide, a chlorsulfuron-resistant biotype of kochia was documented in wheat (Primiani et al., 1990). Since then, there has been a widespread occurrence of kochia biotypes resistant to triazines, sulfonylureas (SU), and imidazolinone (IMI) herbicides (Beckie et al., 2013; Heap, 2016; Kumar et al., 2014). In 1994, dicamba (synthetic auxin)-resistant kochia was first documented in Montana, but it has since been confirmed in North Dakota, Idaho, Nebraska, and Colorado (Cranston et al., 2001; Crespo et al., 2014; Heap, 2016; Preston et al., 2009). Furthermore, glyphosate-resistant (GR) kochia was first reported in Kansas in 2007, then in South 
Dakota in 2009, followed by Nebraska and Colorado in 2011, and Montana and North Dakota in 2012 (Heap, 2016; Kumar et al., 2014; Waite et al., 2013). Additionally, multiple herbicide-resistant kochia biotypes have been reported with resistance to acetolactate synthase (ALS)-and photosystem (PS) II-inhibitors in Illinois and Indiana, and resistance to ALS- and 5-enolpyruvylshikimate-3-phosphate (EPSP) synthase-inhibitors in Montana and western Canada in 2013 (Beckie et al., 2013; Heap, 2016). In this respect, Kochia is similar to Palmer amaranth (Amaranthus palmeri S. Wats) and common waterhemp (Amaranthus rudis Sauer) biotypes that have evolved resistance to atrazine and HPPD-inhibiting herbicides in Nebraska (Jhala et al., 2014; Rana et al., 2013).

Kochia is not a new weed species in Nebraska. It is usually found in the western and southwestern part of the state, but over the past several years it has been reported as problematic further east. Kochia populations resistant to PS II- (triazine) and ALS-inhibiting herbicides (sulfonylureas and imidazolinones) occur in many corn fields in Nebraska (Heap, 2016), and recently, glyphosate- and dicamba-resistant kochia were confirmed in western Nebraska in 2010 and 2011, respectively (Heap, 2016; Crespo et al., 2014). Thus, kochia has evolved resistance to herbicide active ingredients belonging to four different sites of action in Nebraska.

Nebraska ranks $4^{\text {th }}$ in the United States in terms of market value of agricultural products sold, with livestock, corn, and soybean being the top three agricultural products in terms of revenue generated (USDA-NASS, 2012). Corn and soybean cropping systems have a huge impact on the state's economy, and weed control is an important component of the crop production system. In the late 1990s, due to the widespread and repeated use of ALS-inhibiting herbicides, several weed species - including both grasses and broadleaf weeds - evolved resistance to ALS-inhibiting herbicides in several Midwestern states, including Nebraska (Patzoldt et al., 2002; Tranel \& Wright, 2002). With the commercialization of GR crops in 1996, selection pressure from ALS herbicides lessened as glyphosate provided new and effective management of resistant weed species (Shaner, 2014). However, with the increased use of glyphosate, fields in Iowa, Illinois, and Missouri began reporting GR weed species (Culpepper, 2006; Owen, 2002; Rosenbaum \& Bradley, 2013). Additionally, glyphosate and ALS-inhibiting herbicides are predominant chemistries used to control kochia in chemical-fallow, pre-plant burndown, and post-harvest in wheat (Donald \& Prato, 1991; Lloyd et al., 2011; Mickelson et al., 2004; Kumar et al., 2014; Kumar \& Jha, 2015a, 2015b). In a recent research Kumar et al. (2015) reported the underlying mechanisms of glyphosate and ALS resistance in kochia accessions from Montana.

Growers from western Nebraska reported kochia control failure following repeated applications of glyphosate and ALS-inhibiting herbicides, justifying the need to confirm the existence of glyphosate and ALS inhibitor-resistant kochia in Nebraska. The objective of this study was to confirm a kochia biotype resistant to glyphosate and ALS-inhibiting herbicide (tribenuron) by quantifying the level of resistance in a whole plant dose response study. We hypothesized that the putative kochia biotype would be resistant to both glyphosate- and ALS-inhibiting herbicides because of their control failure under field conditions.

\section{Method}

\subsection{Plant Materials}

In 2012, a grower from Sheridan County in western Nebraska reported failure to control kochia following repeated applications of glyphosate and tribenuron methyl. The field in question had been under glyphosate-tolerant corn, conventional spring wheat, and grass seed production for at least eight years, mostly relying on glyphosate and tribenuron for weed control. During fall of 2012, seeds of surviving kochia plants were collected from the same field and considered as a putative-glyphosate and ALS-inhibitors-resistant kochia biotype. Kochia seeds collected in 2010 from a field near Grant, Nebraska with a known history of effective control with the recommended rate of glyphosate and tribenuron were considered as a susceptible biotype and used for comparison in this study.

Seeds were cleaned thoroughly and stored separately in airtight polythene bags at $4{ }^{\circ} \mathrm{C}$ until their use in this study. The seeds were planted in germination trays containing potting mix (Berger BM1 All-Purpose Mix, Berger Peat Moss Ltd., Saint-Modeste, Quebec, Canada). Seedlings were transplanted at the first true leaf stage to square plastic pots $(10 \times 10 \times 12-\mathrm{cm})$ containing a 3:1 mixture of potting mix to soil. Plants were supplied with adequate water and nutrients and kept in a greenhouse maintained at $28^{\circ} \mathrm{C}$ and $24^{\circ} \mathrm{C}$ day and night temperatures, respectively. Artificial lighting was provided using metal halide lamps with $600 \mu$ mol photon $\mathrm{m}^{-2} \mathrm{~s}^{-1}$ light intensity to ensure a $16 \mathrm{~h}$ photoperiod.

\subsection{Whole Plant Dose-Response Study}

Greenhouse whole plant dose-response bioassays were conducted in 2013 at the University of Nebraska-Lincoln to determine the level of resistance in the putative glyphosate-and ALS-inhibitor-resistant kochia biotype. The 
experiments were arranged in a randomized complete block design with four replications. Separate experiments were conducted for glyphosate and ALS-inhibiting herbicides (tribenuron). Single kochia plant per pot was considered as an experimental unit. Glyphosate (Touchdown HiTech ${ }^{\circledR}$, Syngenta Crop Protection, LLC, P.O. Box 18300, Greensboro, NC 27419-8300) treatments included 9 rates $(0,0.125 \times, 0.25 \times, 0.5 \times, 1 \times, 2 \times, 4 \times, 8 \times$, and $16 \times)$, where $1 \times=$ the recommended field rate of glyphosate $\left(870 \mathrm{~g}\right.$ ae ha $\left.{ }^{-1}\right)$. Tribenuron-methyl (Express herbicide, DuPont, 1007 Market Street, Wilmington, Delaware 19898) treatments included 9 rates $(0,0.125$, $0.25 \times, 0.5 \times, 1 \times, 2 \times, 4 \times, 8 \times$, and $16 \times)$, where $1 \times=$ the recommended field rate of tribenuron methyl $(17.5 \mathrm{~g}$ ai $\left.\mathrm{ha}^{-1}\right)$. The 8 - to 10 -cm tall kochia seedlings were treated with glyphosate or tribenuron treatments in a single-tip chamber sprayer (DeVries Manufacturing Corp, Hollandale, MN 56045) fitted with an 8001 E nozzle (TeeJet, Spraying Systems Co., Wheaton, IL 60187) calibrated to deliver $140 \mathrm{~L} \mathrm{ha}^{-1}$ spray volume at $207 \mathrm{kPa}$ at a speed of $4 \mathrm{kmph}$. Each herbicide treatment was prepared in distilled water and mixed with ammonium sulfate (AMS, DSM Chemicals North America Inc., Augusta, GA) at 2.5\% wt/v and nonionic surfactant (NIS, Induce, Helena Chemical Co., Collierville, TN) at $0.25 \%$ v/v.

Visual control estimates were recorded at 7, 14, and $21 \mathrm{~d}$ after treatment (DAT) using a scale ranging from 0 to $100 \%$, with $0 \%$ meaning no control and $100 \%$ meaning complete death or control of kochia. Percent control was assessed on the basis of chlorosis, necrosis, and stunting in plant height compared with nontreated control plants. Aboveground biomass of each kochia plant was harvested at 21 DAT and oven-dried at $65^{\circ} \mathrm{C}$ until it reached a constant weight. The biomass data were converted into percent biomass reduction as compared to the nontreated control (Wortman, 2014).

$$
\text { Percent biomass reduction }=[(C-B) / C] \times 100
$$

Where, $C$ is the mean biomass of the four nontreated control replicates, and $B$ is the biomass of an individual treated experimental unit.

\subsection{Statistical Analysis}

Data were subjected to ANOVA using the PROC MIXED procedure in SAS to test the significance of experimental run, treatment, replication, and treatment-by-experiment interaction. Data from both experiments were pooled on the basis of non-significant experiment run and treatment by experiment interaction; therefore, combined data are presented. For the dose response studies, visual injury estimates and biomass reduction data at 21 DAT were analyzed using a nonlinear regression model with $d r c 1.2$ version package in R 2.3.0 (R statistical software, R Foundation for Statistical Computing, Vienna, Austria; http://www.R-project.org) (Knezevic et al., 2007). Data were subjected to dose response models using a four-parameter log-logistic equation (Seefeldt et al., 1995; Streibig et al., 1993).

$$
Y=C+\{D-C / 1+\exp [B(\log X-\log E)]\}
$$

Where, $Y$ is the response variable based on the visual injury estimate or biomass reduction, $C$ is the lower limit, $D$ is the upper limit, $X$ is the glyphosate or tribenuron dose, $E$ is the glyphosate or tribenuron dose required for $50 \%$ response (e.g., an effective dose, $\mathrm{ED}_{50}$, required to produce $50 \%$ control or biomass reduction), and $B$ is the slope of each curve. Finally, the effective doses of glyphosate or tribenusron required to cause 50 and $90 \%$ injury and biomass reduction at 21 DAT were calculated.

\section{Results and Discussion}

The labeled rate of glyphosate $\left(870 \mathrm{~g} \mathrm{ha}^{-1}\right)$ completely controlled the susceptible kochia biotype, with $670 \mathrm{~g} \mathrm{ha}^{-1}$ of glyphosate required for $90 \%$ control (Table 1). The labeled rate of glyphosate made little to no injury on the putative-resistant kochia biotype (Figure 1), which required 2,516 and 3,781 $\mathrm{g} \mathrm{ha}^{-1}$ of glyphosate to achieve 50 and $90 \%$ control, respectively. The putative-resistant biotype thus exhibited a 6 -fold level of resistance compared to the glyphosate-susceptible biotype (Table 1). Similarly, Beckie et al. (2013) reported the first occurrence of three GR kochia biotypes in western Canada exhibiting resistance levels ranging from 4- to 6-fold. A similar study in Montana on four GR kochia accessions required glyphosate doses of 2350 to $3640 \mathrm{~g} \mathrm{ha}^{-1}$ for $50 \%$ response (Kumar et al., 2014). 
Table 1. Values of $\mathrm{ED}_{50}$ and $\mathrm{ED}_{90}$ for control of kochia biotypes in a dose response to glyphosate and tribenuron at $21 \mathrm{~d}$ after treatment in a greenhouse study conducted at the University of Nebraska-Lincoln

\begin{tabular}{|c|c|c|c|c|c|c|}
\hline \multirow{2}{*}{ Herbicide } & \multirow{2}{*}{ Kochia biotypes } & \multirow{2}{*}{$\begin{array}{l}\mathrm{ED}_{50}( \pm \mathrm{SE}) \\
\left(\mathrm{g} \text { ae } \mathrm{ha}^{-1}\right)\end{array}$} & \multirow{2}{*}{$\begin{array}{l}\mathrm{ED}_{90}( \pm \mathrm{SE}) \\
\left(\mathrm{g} \text { ae } \mathrm{ha}^{-1}\right)\end{array}$} & \multirow{2}{*}{$\begin{array}{l}\text { Resistance } \\
\text { Level }^{\mathrm{a}}\end{array}$} & \multicolumn{2}{|c|}{ Regression Parameters $^{\mathrm{b}}$} \\
\hline & & & & & $\mathrm{B}$ & $\mathrm{D}$ \\
\hline \multicolumn{7}{|l|}{ Glyphosate } \\
\hline & Susceptible & $126(5)$ & $670(53)$ & - & $-1(0.1)$ & $102(1)$ \\
\hline & Resistant & $2516(91)$ & $3781(190)$ & $6 \times$ & $-5(0.5)$ & $99(2)$ \\
\hline \multicolumn{7}{|l|}{ Tribenuron } \\
\hline & Susceptible & $16(0.1)$ & $30(0.2)$ & - & $-4(0.05)$ & $100(0.2)$ \\
\hline & Resistant $^{\mathrm{c}}$ & $150(5)$ & $443(34)$ & $15 \times$ & $-2(0.1)$ & $98(5)$ \\
\hline
\end{tabular}

Note. $\mathrm{ED}_{50}=$ effective dose required to control $50 \%$ population, $\mathrm{ED}_{90}=$ effective dose required to control $90 \%$ population, $\mathrm{SE}=$ standard error. The value in parenthesis is standard error.

${ }^{a}$ Regression parameters B and D for 3-parameter log-logistic model obtained using the nonlinear least-squares function of the statistical software R.

${ }^{\mathrm{b}}$ Resistance level was calculated by dividing $\mathrm{ED}_{90}$ value of resistant biotype by that of the susceptible biotype.

${ }^{c}$ These values have limited biological meaning because $90 \%$ control was not achieved even with the highest rate of glyphosate and tribenuron used in this study.

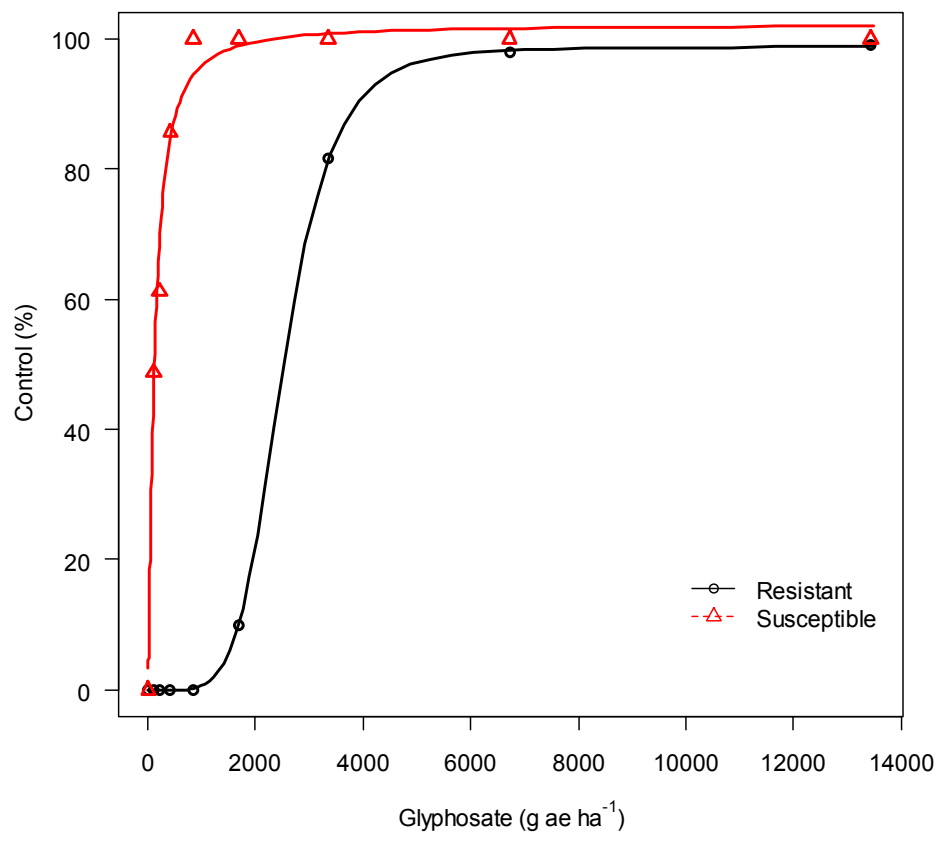

Figure 1. Control of susceptible and resistant kochia biotypes in a dose response to glyphosate at $21 \mathrm{~d}$ after treatment in a greenhouse study conducted at the University of Nebraska-Lincoln

The higher level of resistance to the ALS-inhibiting herbicide (tribenuron) was also observed in the putative-resistant kochia biotype. For example, the $\mathrm{ED}_{90}$ value of the putative-resistant kochia biotype was achieved at $443 \mathrm{~g} \mathrm{ha}^{-1}$ compared with $30 \mathrm{~g} \mathrm{ha}^{-1}$ for the susceptible biotype, thus achieving a 15-fold level of resistance (Figure 2; Table 1). Beckie et al. (2013) also reported a high frequency of ALS-inhibitor herbicide resistance in all confirmed GR kochia populations collected from Alberta, Canada. On the basis of the dose-response curve of shoot biomass reduction, $\mathrm{ED}_{50}$ values for the glyphosate and tribenuron-resistant kochia

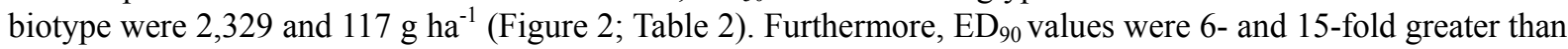
the susceptible biotype and 7 and 10 times the labeled rate of glyphosate and tribenuron, respectively. Tribenuron was never able to provide $>65 \%$ control of the resistant kochia biotype, even with the highest rate $\left(280 \mathrm{~g} \mathrm{ha}^{-1}\right)$ tested (Figure 2; Table 2). 


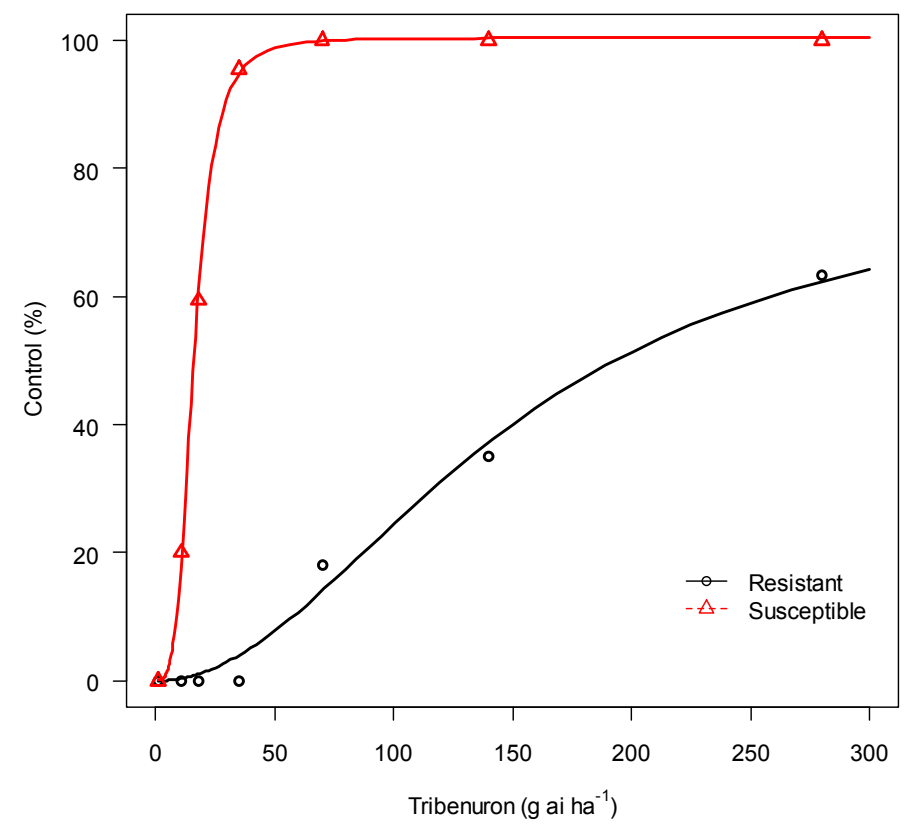

Figure 2. Control of susceptible and resistant kochia biotypes in a dose response to tribenuron at $21 \mathrm{~d}$ after treatment in a greenhouse study conducted at the University of Nebraska-Lincoln

Table 2. Values of $\mathrm{ED}_{50}$ and $\mathrm{ED}_{90}$ for percent biomass reduction of kochia biotypes in a dose response to glyphosate and tribenuron at $21 \mathrm{~d}$ after treatment in a greenhouse study at the University of Nebraska-Lincoln

\begin{tabular}{|c|c|c|c|c|c|}
\hline \multirow{2}{*}{ Herbicide } & \multirow{2}{*}{ Kochia biotypes } & \multirow{2}{*}{$\begin{array}{l}\mathrm{ED}_{50}( \pm \mathrm{SE}) \\
\left(\mathrm{g} \text { ae } \mathrm{ha}^{-1}\right)\end{array}$} & \multirow{2}{*}{$\begin{array}{l}\mathrm{ED}_{90}( \pm \mathrm{SE}) \\
\left(\mathrm{g} \text { ae } \mathrm{ha}^{-1}\right)\end{array}$} & \multicolumn{2}{|c|}{ Regression Parameters $^{\mathrm{a}}$} \\
\hline & & & & $\mathrm{B}$ & $\mathrm{D}$ \\
\hline \multicolumn{6}{|l|}{ Glyphosate } \\
\hline & Susceptible & $639(157)$ & $719(192)$ & $-2.1(0.5)$ & $101(2)$ \\
\hline & Resistant & $2329(353)$ & 4845 (734) & $-1.5(0.1)$ & $74(5)$ \\
\hline \multicolumn{6}{|l|}{ Tribenuron } \\
\hline & Susceptible & $20(2)$ & $47(8)$ & $-2.5(0.5)$ & $102(3)$ \\
\hline & Resistant & $117(17)$ & $463(68)$ & $-1.1(0.1)$ & $95(2)$ \\
\hline
\end{tabular}

Note. $\overline{\mathrm{ED}}_{50}=$ effective dose required for $50 \%$ biomass reduction, $\mathrm{ED}_{90}=$ effective dose required for $90 \%$ biomass reduction, $\mathrm{SE}=$ standard error. The values in parenthesis are standard errors.

${ }^{a}$ Regression parameters B and D for 3-parameter log-logistic model obtained using the nonlinear least-squares function of the statistical software R.

Overall results of the dose response curves suggested that the susceptible kochia biotype was effectively controlled with the labeled rates of glyphosate and tribenuron. The percent visual control dose response analysis showed the GR kochia biotype with a 6-and 15-fold resistance to glyphosate and tribenuron, respectively, relative to the susceptible biotype (Table 1). Biomass reduction data for glyphosate and tribenuron supported the percent visual injury estimates at $21 \mathrm{DAT}$ and suggested a similar level of resistance at the $\mathrm{ED}_{50}$ and $\mathrm{ED}_{90}$ levels (Figure 3; Figure 4). 


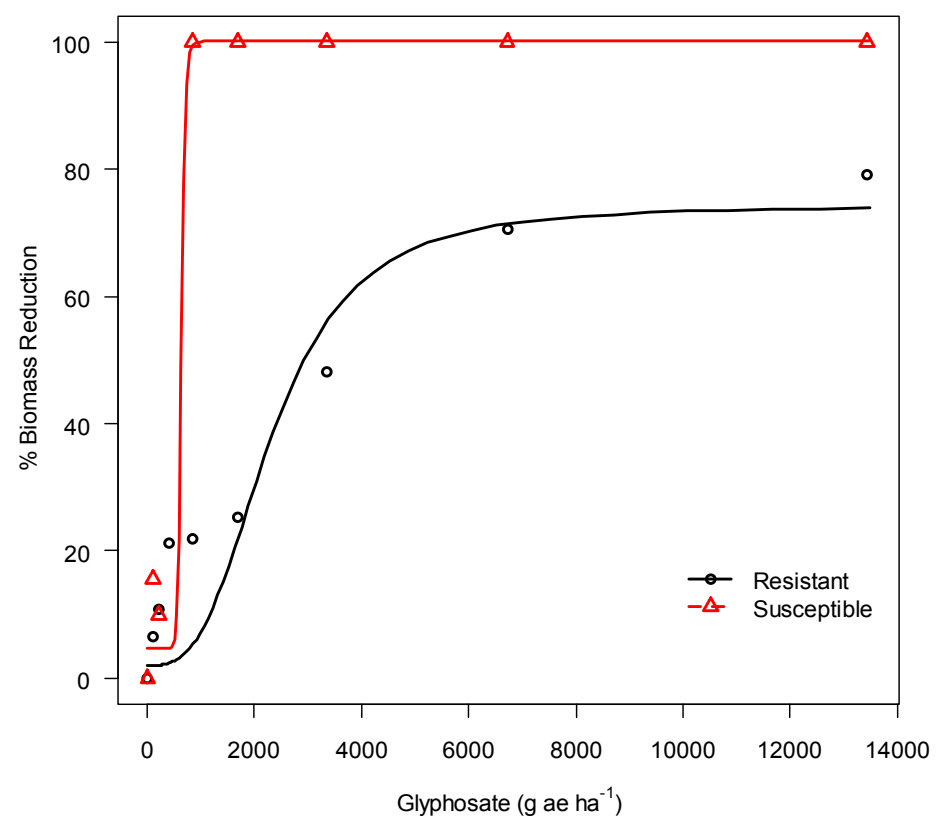

Figure 3. Biomass reduction of susceptible and resistant kochia biotypes in a dose response to glyphosate at $21 \mathrm{~d}$ after treatment in a greenhouse study conducted at the University of Nebraska-Lincoln

The resistant kochia biotype had a 15 -fold level of resistance to POST-applied tribenuron. The level of ALS-resistance is likely much higher, since the highest dose only provided 63\% control (Figure 2) and 46\% biomass reduction (Figure 4).

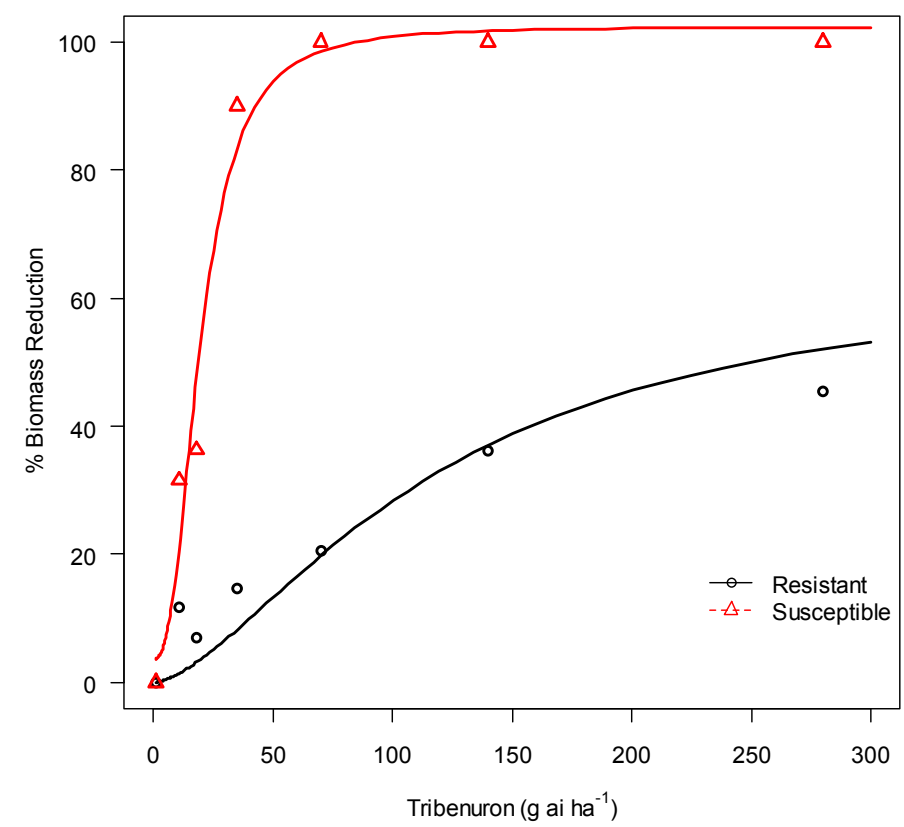

Figure 4. Biomass reduction of susceptible and resistant kochia biotypes in a dose response to tribenuron at $21 \mathrm{~d}$ after treatment in a greenhouse study conducted at the University of Nebraska-Lincoln

Weed management and containment efforts to control herbicide-resistant weeds are highly influenced by the adoption of best management practices by growers (Norsworthy et al., 2012). The putative-resistant kochia 
biotype from the production field in Nebraska is resistant to both glyphosate and ALS-inhibiting herbicides. In the Midwestern United States, kochia was one of the first weed species to evolve resistance to several herbicide chemistries, including synthetic auxins and EPSP synthase inhibitors (Primiani et al., 1990; Beckie et al., 2013). Glyphosate and tribenuron are important weed control options that can be applied POST or pre-seeding (burndown), in-crop, or in chemical-fallow situations in glyphosate-resistant crops and most cereal crops. With the evolution of multiple-herbicide resistance there would be no registered in-crop herbicides to control the multiple-herbicide resistant biotype in sunflower (Helianthus annuus L.), lentil (Lens culinaris Medik), chickpea (Cicer arietinum L.), dry bean (Phaseolus vulgaris L.), soybean, or potato (Solanum tuberosum L.). Glyphosate and tribenuron could still be used to control other troublesome broadleaf and grass weed species, but the growers would have to modify their practices to control kochia using other cultural, physical or chemical practices. Due to the evolution of EPSP synthase and ALS-inhibitor-resistant kochia biotype, weed management in these crop production systems will be challenging. Therefore, integrated weed management strategies including crop rotation, tillage, and a PRE followed by POST herbicide program with effective sites of action will be required for the control of EPSP synthase and ALS-inhibiting herbicide-resistant kochia biotype.

\section{References}

Anderson, R. L., \& Nielsen, D. C. (1996). Emergence pattern of five weeds in the central Great Plains. Weed Technology, 10, 744-749.

Beckie, H. J., Blackshaw, R. E., Low, R., Hall, L. M., Sauder, C. A., Martin, S., ... Shirriff, S. W. (2013). Glyphosate- and acetolactate synthase inhibitor-resistant kochia (Kochia scoparia) in western Canada. Weed Science, 61, 310-318. http://dx.doi.org/10.1614/WS-D-12-00140.1

Casey, P. A. (2009). Plant Guide for Kochia (Kochia scoparia). USDA-Natural Resources Conservation Service, Kansas Plant Materials Center, Manhattan, KS.

Cranston, H. J., Kern, A. J., Hackett, J. L., Miller, E. K., Maxwell, B. D., \& Dyer, W. E. (2001). Dicamba resistance in Kochia. Weed Science, 49, 164-170. http://dx.doi.org/10.1614/0043-1745(2001)049[0164: DRIK]2.0.CO;2

Crespo, R. J., Bernards, M. L., Sbatella, G. M., Kruger, G. R., Lee, D. J., \& Wilson, R. G. (2014). Response of Nebraska Kochia (Kochia scoparia) Accessions to Dicamba. Weed Technology, 28, 151-162. http://dx.doi.org/10.1614/WT-D-13-00109.1

Culpepper, A. S. (2006). Glyphosate-induced weed shifts. Weed Technology, 20, 277-281. http://dx.doi.org/10.1614/WT-04-155R.1

Dodd, J., \& Moore, J. H. (1993). Introduction and status of Kochia scoparia in western Australia. Proceedings of the 10th Australian and 14th Asian-Pacific Weeds Conference, 1, 496-500.

Donald, W. W., \& Prato, T. (1991). Profitable, effective herbicides for planting-time weed control in no-till spring wheat (Triticum aestivum). Weed Science, 39, 83-90.

Durgan, B. R., Dexter, A. G., \& Miller, S. D. (1990). Kochia (Kochia scoparia) interference in sunflower (Helianthus annuus). Weed Technology, 4, 52-56.

Forcella, F. (1985). Spread of kochia in the northwestern United States. Weeds Today, 16, 4-6.

Friesen, L. F., Beckie, H. J., Warwick, S. I., \& Van Acker, R. C. (2009). The biology of Canadian weeds. 138. Kochia scoparia (L.) Schrad. Canadian Journal of Plant Science, 89, 141-167. http://dx.doi.org/10.4141/CJPS08057

Heap, I. (2016). International Survey of Herbicide Resistant Weeds. Retrieved April, 2016, from http://www.weedscience.org

Jhala, A. J., Sandell, L. D., Rana, N., Kruger, G. R., \& Knezevic, S. Z. (2014). Confirmation and control of triazine and 4-Hydroxyphenylpyruvate dioxygenase-inhibiting herbicide-resistant Palmer amaranth (Amaranthus palmeri) in Nebraska. Weed Technology, 28, 28-38. http://dx.doi.org/10.1614/WT-D13-00090.1

Knezevic, S. Z., Streibig, J. C., \& Ritz, C. (2007). Utilizing R software package for dose-response studies: the concept and data analysis. Weed Technology, 21, 840-848. http://dx.doi.org/10.1614/WT-06-161.1

Kumar, V., \& Jha, P. (2015a). Effective preemergence and postemergence herbicide programs for kochia control. Weed Technology, 29, 24-34. http://dx.doi.org/10.1614/WT-D-14-00026.1 
Kumar, V., \& Jha, P. (2015b). Influence of herbicides applied postharvest in wheat stubble on control, fecundity, and progeny fitness of Kochia scoparia in the US Great Plains. Crop Protection, 71, 144-149. http://dx.doi.org/10.1016/j.cropro.2015.02.016

Kumar, V., Jha, P., \& Reichard, N. (2014). Occurrence and characterization of kochia (Kochia scoparia) accessions with resistance to glyphosate in Montana. Weed Technology, 28, 122-130. http://dx.doi.org/10.1614/WT-D-13-00115.1

Kumar, V., Jha, P., Giacomini, D., Westra, E. P., \& Westra, P. (2015). Molecular basis of evolved resistance to glyphosate and Acetolactate Synthase-Inhibitor herbicides in kochia (Kochia scoparia) accessions from Montana. Weed Science, 63, 758-769. http://dx.doi.org/10.1614/WS-D-15-00021.1

Lloyd, K. L., Johnson, J. M., Gover, A. E., \& Sellmer, J. C. (2011). Preemergence and postemergence suppression of kochia on rights-of-way. Weed Technology, 25, $292-297$. http://dx.doi.org/10.1614/WT-D-10-00117.1

Mickelson, J. A., Bussan, A. J., Davis, E. S., Hulting, A. G., \& Dyer, W. E. (2004). Postharvest kochia (Kochia scoparia) management with herbicides in small grains. Weed Technology, 18, 426-431. http://dx.doi.org/10.1614/WT-03-164R1

Norsworthy, J. K., Ward, S. M., Shaw, D. R., Llewellyn, R. S., Nichols, R. L., Webster, T. M., ... Barrett, M. (2012). Reducing the risks of herbicide resistance: best management practices and recommendations. Weed Science, 60, 31-62. http://dx.doi.org/10.1614/WS-D-11-00155.1

Nussbaum, E. S., Wiese, A. F., Crutchfield, D. E., Chenault, E. W., \& Lavake, D. (1985). The effect of temperature and rainfall on emergence and growth of eight weeds. Weed Science, 33, 165-170.

Owen, M. D. K. (2002). Glyphosate resistant waterhemp in Iowa. Proceedings of North Central Weed Science Society, 57, 210.

Primiani, M. M., Cotterman, J. C., \& Saari, L. L. (1990). Resistance of Kochia scoparia to sulfonylurea and imidazolinone herbicides. Weed Technology, 4, 169-172.

Rana, N., Knezevic, S. Z., \& Scott, J. (2013). HPPD-resistant waterhemp in Nebraska. Proceedings of 2013 Crop Production Clinics (pp. 165-171). Lincoln, NE: University of Nebraska-Lincoln Extension.

Rosenbaum, K. K., \& Bradley, K. W. (2013). A Survey of Glyphosate-Resistant Waterhemp (Amaranthus rudis) in Missouri Soybean Fields and Prediction of Glyphosate Resistance in Future Waterhemp Populations Based on In-Field Observations and Management Practices. Weed Technology, 27, 656-663. http://dx.doi.org/10.1614/WT-D-13-00042.1

Schwinghamer, T. D., \& Van Acker, R. C. (2008). Emergence timing and persistence of kochia (Kochia scoparia). Weed Science, 56, 37-41. http://dx.doi.org/10.1614/WS-07-098.1

Seefeldt, S. S., Jensen, J. E., \& Fuerst, E. P. (1995). Log-logistic analysis of herbicide dose-response relationships. Weed Technology, 9, 218-227.

Shaner, D. L. (2014). Lessons learned from the history of herbicide resistance. Weed Science, 62, $427-431$. http://dx.doi.org/10.1614/WS-D-13-00109.1

Streibig, J. C., Rudemo, M., \& Jensen, J. E. (1993). Dose-response curves and statistical models. In J. C. Streibig, \& P. Kudsk (Eds.), Herbicide Bioassays (pp. 29-55). Boca Raton, FL: CRC.

Waite, J., Thompson, C. R., Peterson, D. E., Currie, R. S., Olson, B. L. S., Stahlman, P. W., \& Khatib, K. A. (2013). Differential Kochia (Kochia scoparia) Populations Response to Glyphosate. Weed Science, 61, 193-200. http://dx.doi.org/10.1614/WS-D-12-00101.1

Weatherspoon, D. M., \& Schweizer, E. E. (1969). Competition between kochia and sugarbeets. Weed Science, 17, 464-467.

Wicks, G. A., Martin, A. R., \& Mahnken, G. W. (1993). Control of triazine-resistant kochia (Kochia scoparia) in conservation tillage corn (Zea mays). Weed Science, 41, 225-231.

Wicks, G. A., Martin, A. R., Haack, A. E., \& Mahnken, G. W. (1994). Control of triazine-resistant kochia (Kochia scoparia) in sorghum (Sorghum bicolor). Weed Technology, 8, 748-753.

Wortman, S. E. (2014). Integrating weed and vegetable crop management with multifunctional air propelled abrasive grits. Weed Technology, 28, 243-252. http://dx.doi.org/10.1614/WT-D-13-00105.1 


\section{Copyrights}

Copyright for this article is retained by the author(s), with first publication rights granted to the journal.

This is an open-access article distributed under the terms and conditions of the Creative Commons Attribution license (http://creativecommons.org/licenses/by/4.0/). 